\title{
Revisiting the dataflow principle for chemical information processing
}

\author{
Wolf D Ihlenfeldt \\ From 7th German Conference on Chemoinformatics: 25 CIC-Workshop \\ Goslar, Germany. 6-8 November 2011
}

Dataflow systems, such as Pipeline Pilot or KNIME have become important mainstream tools for data processing in chemistry. These established systems are all implemented relying on a data model emphasizing a strict row/column-centric data table view which does not facilitate interaction with individual chemistry objects, or non-uniform data contents.

Resuming our pioneering work which resulted in the implementation of the first dataflow system for chemistry [1], we present in this contribution a different, objectcentric approach for the design of re-usable chemical information processing sequences. Our system is based on the metaphor of a factory floor, instead of opaque pipelines. Individual machining stations perform configurable processing steps on objects such as structures, reactions, datasets or tables. Objects are transported between these - or temporarily set on the factory floor for storage or inspection. The combination of this general concept with the extensive scripting functionality of the Cactvs Chemoinformatics toolkit results in a system with capabilities notably different and more flexible than standard pipelining systems.

Published: 1 May 2012

\section{Reference}

1. Ihlenfeldt, Takahashi, Abe : . Proc. 28th Annual Hawaii International Conference on System Sciences 1995, 227-236.

doi:10.1186/1758-2946-4-S1-P15

Cite this article as: Ihlenfeldt: Revisiting the dataflow principle for chemical information processing. Journal of Cheminformatics 20124 (Suppl 1):P15.

Publish with ChemistryCentral and every scientist can read your work free of charge

"Open access provides opportunities to our colleagues in other parts of the globe, by allowing anyone to view the content free of charge."

W. Jeffery Hurst, The Hershey Company.

- available free of charge to the entire scientific community

- peer reviewed and published immediately upon acceptance

- cited in PubMed and archived on PubMed Central

- yours - you keep the copyright

Submit your manuscript here:

http://www.chemistrycentral.com/manuscript/

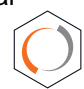

ChemistryCentral 